\title{
Assessing the potential of utilization and storage strategies for post-combustion $\mathrm{CO}_{2}$ emissions reduction
}

\author{
Katy Armstrong and Peter Styring* \\ UK Centre for Carbon Dioxide Utilization, Department of Chemical and Biological Engineering, The University of Sheffield, Sheffield, UK
}

Edited by:

Suojiang Zhang, Chinese Academy of

Sciences, China

\section{Reviewed by:}

Xuezhong He, Norwegian University of Science and Technology, Norway Wei Liu, Pacific Northwest National Laboratory, USA

\section{${ }^{*}$ Correspondence:}

Peter Styring, UK Centre for Carbon Dioxide Utilization, Department of Chemical and Biological Engineering, The University of Sheffield, Sir Robert Hadfield Building, Sheffield S1 3JD, UK

e-mail: p.styring@sheffield.ac.uk
The emissions reduction potential of three carbon dioxide handling strategies for postcombustion capture is considered. These are carbon capture and sequestration/storage (CCS), enhanced hydrocarbon recovery (EHR), and carbon dioxide utilization (CDU) to produce synthetic oil. This is performed using common and comparable boundary conditions including net $\mathrm{CO}_{2}$ sequestered based on equivalent boundary conditions. This is achieved using a "cradle to grave approach" where the final destination and fate of any product is considered. The input boundary is pure $\mathrm{CO}_{2}$ that has been produced using a post-combustion capture process as this is common between all processes. The output boundary is the emissions resulting from any product produced with the assumption that the majority of the oil will go to combustion processes. We also consider the "cradle to gate" approach where the ultimate fate of the oil is not considered as this is a boundary condition often applied to EHR processes. Results show that while CCS can make an impact on $\mathrm{CO}_{2}$ emissions, CDU will have a comparable effect whilst generating income while EHR will ultimately increase net emissions. The global capacity for CDU is also compared against CCS using data based on current and planned CCS projects. Analysis shows that current CDU represent a greater volume of capture than CCS processes and that this gap is likely to remain well beyond 2020 which is the limit of the CCS projects in the database.

Keywords: $\mathrm{CDU}, \mathrm{CCU}$, enhanced oil recovery, $\mathrm{CCS}, \mathrm{LCA}, \mathrm{CO}_{2}$ reduction potential

\section{INTRODUCTION}

Society is realizing that we have reached a critical point in our approach to energy use and resulting emissions. There exists an "energy trilemma" where we must consider the security of the energy supply, the costs of that energy, and the environmental impacts created (World Energy Council, 2013). The carbon dioxide utilization (CDU) for chemical synthesis is a growing area of research. Carbon dioxide $\left(\mathrm{CO}_{2}\right)$ can be used as a valuable feedstock for chemical production and chemical energy storage (Styring et al., 2014). This impacts on two of the key challenges in the trilemma: the sustainable supply of chemicals and meeting energy demand whilst also reducing $\mathrm{CO}_{2}$ emitted to the atmosphere. In treating $\mathrm{CO}_{2}$ as a commodity chemical rather than a waste, it becomes a valuable asset rather than an economic drain. Fossil oils are the primary feedstock for many industrial chemicals, but these are not sustainable as while there is a plentiful reserve of fossil oil and gas, this will ultimately lead to new $\mathrm{CO}_{2}$ emissions when the chemical is used (Berners-Lee and Clark, 2013; McGlade and Ekins, 2015). If emitted $\mathrm{CO}_{2}$ is used as an alternative carbon source for the production of these products, net emissions will be reduced and a sustainable pathway for production will be created. $\mathrm{CO}_{2}$ utilization technologies can either give products that sequester the $\mathrm{CO}_{2}$ for a lengthy period of time (such as polymers or mineralization) or only for a matter of weeks or days as in the case of hydrocarbon fuels and methanol. However, in the case of fuels, we must also consider longer term storage as is the case with seasonal storage: using renewable power to produce liquid and gaseous fuels that can be stockpiled until they are needed.

It is a misconception that manufacturing fuels and other short lifetime chemicals by $\mathrm{CDU}$ will not lead to a reduction in $\mathrm{CO}_{2}$. These products would traditionally be sourced from fossil oils and once combusted or used would release $\mathrm{CO}_{2}$ to the atmosphere. It is acknowledged that there are substantial reserves of fossil hydrocarbons, however these are so great that ultimately we will not have the capacity to deal with the emissions from them while trying to achieve the two degree scenario for climate change mitigation (IPCC, 2007). When manufacturing chemicals from $\mathrm{CO}_{2}$, previously emitted $\mathrm{CO}_{2}$ will be re-used before it is re-emitted, resulting in a net reduction in emitted $\mathrm{CO}_{2}$. This is of course a consequence of carbon avoided. While this does not sequester as much $\mathrm{CO}_{2}$ as if it was stored geologically or is used to produce long life-time products such as a polymer or mineral; but it does provide a sustainable low carbon pathway for the chemicals industry and a net reduction in emissions. This net reduction and the amount of $\mathrm{CO}_{2}$ that can be utilized to create it should not be disregarded. The chemicals industry needs to become more sustainable and embrace a circular economy and the use of $\mathrm{CO}_{2}$ as a feedstock enables this (Centi et al., 2013).

$\mathrm{CO}_{2}$ is a greenhouse gas (GHG) created as an anthropogenic waste product by power generation and many industrial processes. Energy-related emissions of $\mathrm{CO}_{2}$ in 2013 were $36 \mathrm{Gt}$ (Carbon Dioxide Information Analysis Centre, 2014), and predicted to rise to 43 Gt by 2030 (IEA Energy Technology Perspectives, 2014). The 
Doha amendment to the Kyoto Protocol (2012) gives a commitment to aim to reduce GHG emissions by at least $18 \%$ below 1990 levels between 2013 and 2020. In the UK, the 2008 Climate Change Act set a legally binding target to reduce the UK's $\mathrm{CO}_{2}$ equivalent emissions amount by at least $80 \%$ from the 1990 baseline by 2050 .

Different strategies to reduce $\mathrm{CO}_{2}$ emissions must be employed to reach these targets (Figure 1). The IEA has calculated that in order to give a $50 \%$ chance of restricting global warming to $2^{\circ} \mathrm{C}$, $\mathrm{CO}_{2}$ emissions must be reduced by $17 \mathrm{Gt}$ in 2030 and $39 \mathrm{Gt}$ in 2050 against projected emissions. To achieve this, the IEA has modeled $\mathrm{CO}_{2}$ reductions scenarios, which include carbon capture and storage (CCS), renewables, end-use fuel and electricity efficiency, end-use fuel switching, nuclear power and power generation efficiency, and fuel switching, to give the desired outcome of a less than $+2^{\circ} \mathrm{C}$ rise. Of these technologies, CDU is most often compared with CCS due to the similarities in the capture of $\mathrm{CO}_{2}$, although how the captured $\mathrm{CO}_{2}$ is dealt with is often very different.

In CCS, $\mathrm{CO}_{2}$ is captured from emitters, separated from the other emitted gases, then compressed and transported, usually via a pipeline, to a geological storage site. These are often a depleted natural gas/oil wells or a saline aquifers. CCS is an effective method of reducing $\mathrm{CO}_{2}$ emissions to the atmosphere, but is costly with an estimated $30 \%$ parasitic energy loss for a power generator, as well as substantial capital (CAPEX) and operational (OPEX) costs.

There has been considerable debate as to the relative impacts of different carbon capture technologies. It has been a long held belief that CCS represents the best option for carbon dioxide mitigation while giving the cheapest approach to carbon-neutral fuels, still using existing fossil fuel reserves. Furthermore, it is assumed that $\mathrm{CO}_{2}$ use through enhanced hydrocarbon recovery (EHR) in the form of oil or natural gas will aid the economics of the capture process. It has also been suggested that carbon dioxide capture and utilization (CCU or CDU) will only play a minor role due to the huge volumes of $\mathrm{CO}_{2}$ that need to be sequestered. In order to address these issues, we have undertaken a number of studies to assess the techno-economic and environmental viability of each of the processes. This has included considering "cradle to gate" and "cradle to grave" scenarios for different technologies in terms of material balances across the processes. Each of the three processes is considered with a common feedstock: captured and purified carbon dioxide that is piped to the point of storage or utilization.

\section{CARBON CAPTURE AND STORAGE}

The global status of CCS projects has been compiled by the Global CCS Institute database (2014) "Status of CCS database." The database divides current and proposed CCS plants according to their phase of development: Operate; Execute; Define; Evaluate; Identify. The nature of the capture process is identified, as is the ultimate destination of the $\mathrm{CO}_{2}$. There are 55 CCS projects currently listed on the database, with a potential capacity of storing approximately $102 \mathrm{Mt} \mathrm{CO}_{2}$ /year by 2020 as shown in Table 1.

Of these projects, 13 are in the Operate phase with the majority being located in North America. Of this group of projects, only one is associated with the power generation sector: the Sask Power facility at Boundary Dam in Canada which came online in 2014. The facility has a $1 \mathrm{Mt}$ /year capture capacity and the $\mathrm{CO}_{2}$ will be transported by a $66-\mathrm{km}$ pipeline to an enhanced oil recovery (EOR) facility. The Boundary Dam project represents the highest single unit capture facility globally, although there are plans for the Gorgon Carbon Dioxide Injection Project in Western Australia to come online in 2016 with the world's largest capture capacity of 3 $4 \mathrm{Mt} /$ year. Only two facilities in the Operate phase are in mainland Europe, the Sleipner and Snøhvit projects in Norway that take $\mathrm{CO}_{2}$ from natural gas processing plants and store the gas in dedicated geological storage facilities. Taking the operational plants only, the current total global capacity is $26.6 \mathrm{Mt}$ /year. If we now include

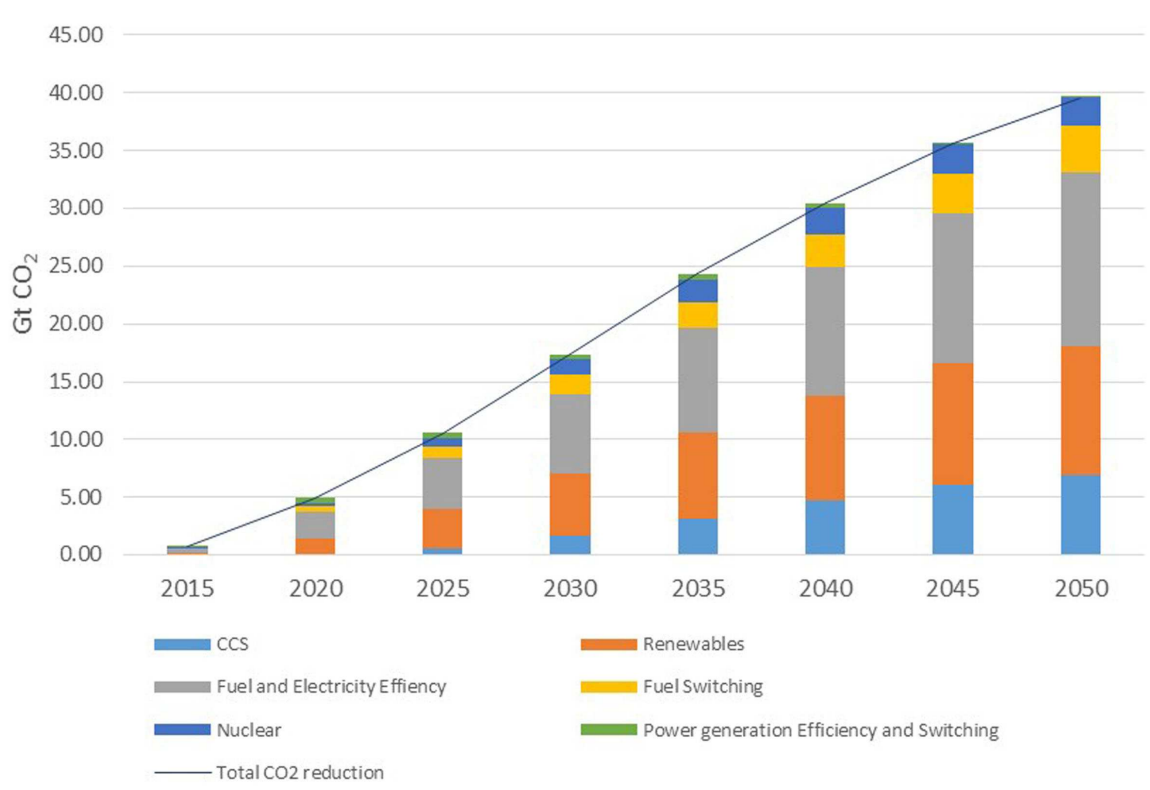

FIGURE 1 |World $\mathrm{CO}_{2}$ reduction targets to meet the $2^{\circ} \mathrm{C}$ scenario (2DS) adapted from IEA Energy Technology Perspectives (2014). 
Table 1 |The global status of CSS projects in 2014 [adapted from Global CCS Institute database (2014)].

\begin{tabular}{|c|c|c|c|c|c|}
\hline \multirow{2}{*}{$\begin{array}{l}\text { Type of plant } \\
\text { Chemical production }\end{array}$} & \multirow{2}{*}{$\begin{array}{c}\text { No. of projects } \\
5\end{array}$} & \multirow{2}{*}{$\begin{array}{l}\text { Type of capture } \\
\text { Two industrial separation }\end{array}$} & \multirow{2}{*}{$\begin{array}{l}\text { Storage method } \\
3 \text { EOR }\end{array}$} & \multicolumn{2}{|c|}{ Total $\mathrm{CO}_{2} \mathrm{Mt} /$ year } \\
\hline & & & & 4.96 & $8-9$ \\
\hline & & Three pre-combustion & 2 Geological & $3-4$ & \\
\hline & & & 1 Geological & 1 & \\
\hline & & & 1 Unspecified & 2 & \\
\hline \multirow[t]{2}{*}{$\mathrm{H}_{2}$ production } & 2 & Industrial separation & $1 \mathrm{EOR}$ & 1 & 2 \\
\hline & & & 1 Geological & 1 & \\
\hline Iron and steel & 1 & Industrial separation & EOR & \multicolumn{2}{|c|}{0.8} \\
\hline \multirow[t]{2}{*}{ Natural gas processing } & 13 & Pre-combustion & $8 \mathrm{EOR}$ & 22.4 & $29.6-30.1$ \\
\hline & & & 5 Geological storage & $7.2-7.7$ & \\
\hline Synthetic natural gas & 2 & 2 Pre-combustion & 2 EOR & \multicolumn{2}{|c|}{8.5} \\
\hline Unknown & 1 & Unknown & Geological & 1 & \\
\hline Total & 55 & & & \multicolumn{2}{|c|}{102.3} \\
\hline
\end{tabular}

those projects in the Execute phase, then the total capacity rises to 34.7 Mt/year as there are an additional nine projects assigned to this phase. None of these are in mainland Europe. Extending this to include projects in the Define phase, there are 14 projects identified which includes 4 projects in the UK and 1 in the Netherlands. However, it is noted that three of these are currently on hold and only the Peterhead and White Rose projects in the UK are in the Front End Engineering Design (FEED) stage. If we still include the mothballed projects, the total global emissions capture total a maximum of $58.5 \mathrm{Mt}$ /year. Of the 36 projects in this latter total, only 12 are dedicated geological storage project (although one may adapt into an EOR project) and 24 are EOR projects. Of the 13 projects currently in operation, 10 are EOR installations. By contrast, the Carbon Recycling International $\mathrm{CO}_{2}$ to methanol plant in Iceland currently produces $4 \mathrm{Mt}$ /year consuming $5.5 \mathrm{Mt} /$ year $\mathrm{CO}_{2}$. This is larger than any current or proposed single CCS facility. The energy for the conversion comes from a geothermal source and avoids fossil fuels. This emphasizes the importance of renewable energy in any CDU process. Likewise, it emphasizes the importance of CDU in seasonal energy storage through the production of synthetic gas or liquid fuels.

The database is extensive and describes each process, including capacity, operational phase, and origin of the $\mathrm{CO}_{2}$ and its destination in storage or HER facilities. It provides an up to date analysis of all project that could come online by 2020 . The spreadsheet is too detailed to discuss in this paper and readers are advised to consult it directly. It is available free of charge from the GCCSI reference given above.

\section{CARBON DIOXIDE ENHANCED OIL/HYDROCARBON RECOVERY ( $\mathrm{CO}_{2}$-EOR/EHR)}

Carbon dioxide can also be used in EOR or more generally, to include natural gas, EHR. This is similar in many ways to CCS as captured and compressed $\mathrm{CO}_{2}$ is injected into geological formations. However, these contain trapped hydrocarbons which can be displaced by the injected $\mathrm{CO}_{2}$. In a perfect case of immiscible EOR, the hydrocarbon and $\mathrm{CO}_{2}$ are completely immiscible so do not mix. Instead, an equal volume of hydrocarbon is forced out of the well to be replaced by the $\mathrm{CO}_{2}$. Therefore, the $\mathrm{CO}_{2}$ is sequestered in the geological structure. By contrast, miscible EOR involves the mixing of the $\mathrm{CO}_{2}$ and hydrocarbon. Some of the $\mathrm{CO}_{2}$ is released together with the hydrocarbon while a proportion is sequestered. The relative proportions are dictated by the degree of mixing achieved. In fact, the $\mathrm{CO}_{2}$ released will be recaptured and re-injected into the formation, however to account for this in the functional unit, it must be considered as being non-sequestered in the single pass first injection. Any gas re-injected would necessarily reduce subsequent functional units of $\mathrm{CO}_{2}$, so would perturb calculations. In EHR, the product is a hydrocarbon; typically crude oil or natural gas. Therefore, unlike CCS, EHR will produce a product that on refining will represent commercial value. Hydrocarbons that are otherwise uneconomic to extract are therefore suitable for EHR technologies and this is the general driving force.

\section{CARBON DIOXIDE UTILIZATION}

In $\mathrm{CDU}, \mathrm{CO}_{2}$ is used as a carbon source to produce new, marketable products. It is in essence $\mathrm{CO}_{2}$ reuse. CDU technologies can either give products that sequester the $\mathrm{CO}_{2}$ for a lengthy period of time (such as polymers or mineralization); or only for a matter of weeks or days but also perhaps between seasons, as in the case of fuels and methanol. There are many methods for CDU available which include catalytic reduction and direct addition. A full discussion of these methods is beyond the scope of this paper, so readers are recommended to refer to reviews and textbooks that cover the field in depth [for example Aresta et al. (2013) and Styring et al. (2014)]. However, as many of these chemicals 
would traditionally be sourced from petrochemicals, manufacturing them from $\mathrm{CO}_{2}$ will result in a net reduction in emitted $\mathrm{CO}_{2}$ as shown schematically in Figure 2. We should also note that there is a growing interest in harnessing biological processes in CDU, often coupled to the use of renewable energy integration. These include the cultivation of algae and micro-algae in photo-reactors or open raceways (Jansen et al., 2011). This raises issues of sustainability, characterized by the energy-water-food nexus, primarily through the use of agricultural land for energy-related processes. Consequently, there are concerns whether such processes would be economically viable at scale (Aresta et al., 2013), especially given the concurrent needs for food, energy, and chemicals. The concept of the bio-refinery and advanced bio-manufacturing may go some way to addressing this, together with genetic modification of associated organisms, although this has its own controversies. While this paper does not address bioprocesses, it is acknowledged that once algae are harnessed for enhanced aquatic biomass production, there is the potential for large impact. Aresta et al. (2005, 2013) and Aresta and Dibenedetto (2010) have proposed that production could approach 600-700 Mt in 2020 and 3,000-4,000 Mt by 2050 . However, while aquatic algae production appears feasible, land-based production is a challenge.

Carbon dioxide utilization is not a new technology. $\mathrm{CO}_{2}$ has been used to produce urea for many decades. Currently, $\mathrm{CO}_{2}$ utilization processes such as urea and methanol production use $122 \mathrm{Mt}$ of $\mathrm{CO}_{2}$ annually as seen in Table 2 [adapted from Aresta et al. (2013)]. This by far exceeds the current amount of $\mathrm{CO}_{2}$ captured by CCS which is $26.6 \mathrm{Mt} /$ year.

\section{COMPARING APPROACHES TO $\mathrm{CO}_{2}$ CAPTURE, STORAGE, AND UTILIZATION TECHNOLOGIES}

To date, there have been few studies on the whole systems, and in particular there are no comparative studies between the complementary $\mathrm{CO}_{2}$ post-emission handling technologies. To consider a relative assessment, we have made a number of assumptions in order to simplify the argument starting from a common input. We have assumed that the $\mathrm{CO}_{2}$ supply originates from a power generator or an industrial emitter and that the $\mathrm{CO}_{2}$ is captured and concentrated on site to produce a common $\mathrm{CO}_{2}$ stream entering the processes compared. In all cases, the captured and purified gas will need to be transported to its final destination. For the purpose of comparison, it is assumed that this will be using a dedicated pipeline. For CCS and EHR, the pipeline is necessary between the capture and the storage site. For CDU, it is proposed that a spur on the pipeline can take a slipstream from the main flow to be diverted to the chemicals or synthetic fuels plant. Of course, ideally the CDU plant would be situated close to the capture plant in order to reduce costs. Therefore, as these processes are common, we neglect the GHG emissions in the early part of the supply chain up to and including the transportation of the $\mathrm{CO}_{2}$ from the capture step. We then compare the net $\mathrm{CO}_{2}$ sequestration at the storage site as the first end boundary condition and then on consumption of the product produced (fuel combustion) as the second end boundary condition.

In order to compare CCS, $\mathrm{CO}_{2}-\mathrm{EOR}$, and CDU, it is necessary to define a functional unit for the analysis. As there is no product in CCS then an initial functional unit has been chosen to be $1 \mathrm{~m}^{3}$ $\mathrm{CO}_{2}$ input into a process. This can be later scaled or transferred to an alternative functional unit depending on the exact process. For CCS and $\mathrm{CO}_{2}$-EOR, $1 \mathrm{~m}^{3}$ of the gas is injected under supercritical conditions into a cavity of $1 \mathrm{~m}^{3}$. We have taken the density of $\mathrm{CO}_{2}$ to be that of the super critical fluid at the critical point, which is $469 \mathrm{~kg} \mathrm{~m}^{-3}$. In CCS, the cavity (or pores) is regarded as being empty, or filled with saline water, while in $\mathrm{CO}_{2}-\mathrm{EOR}$, the cavity contains crude oil with an average density of $900 \mathrm{~kg} \mathrm{~m}^{-3}$ and an average molecular formula equivalent to $\mathrm{C}_{19} \mathrm{H}_{40}\left(248 \mathrm{~kg} \mathrm{kmol}^{-1}\right)$. For CDU, $1 \mathrm{~m}^{3}$ of $\mathrm{CO}_{2}$ is reduced with hydrogen in a power to liquid process to yield nonadecane $\left(\mathrm{C}_{19} \mathrm{H}_{40}\right)$, analogous in molecular weight to the crude oil above.

In the case of CCS, the $\mathrm{CO}_{2}$ is simply injected into the cavity under supercritical conditions. The density of $\mathrm{scCO}_{2}$ is taken to be $469 \mathrm{~kg} \mathrm{~m}^{-3}$ and so $469 \mathrm{~kg}$ are sequestered. Therefore, the net sequestration of $\mathrm{CO}_{2}$ is $+469 \mathrm{~kg}$. For $\mathrm{CO}_{2}$-EOR, there are a number of scenarios depending on the miscibility of the $\mathrm{CO}_{2}$ with the oil or gas. We will consider two scenarios that liberate the trapped oil. Firstly, this may result from an immiscible injection process whereby $1 \mathrm{~m}^{3}$ of oil is displaced by $1 \mathrm{~m}^{3}$ of $\mathrm{scCO}_{2}$. This will liberate $900 \mathrm{~kg}$ of crude oil at the well head, while $469 \mathrm{~kg} \mathrm{CO}_{2}$ are sequestered. Again there will be a net sequestration of $\mathrm{CO}_{2}$ at the well head of $+469 \mathrm{~kg}$. We also consider a miscible mixing process whereby there is complete mixing to give $50 \% \mathrm{CO}_{2}$ and $50 \%$ crude oil. Assuming ideal mixing, $469 \mathrm{~kg} \mathrm{CO}_{2}$ and $900 \mathrm{~kg}$ oil will mix to
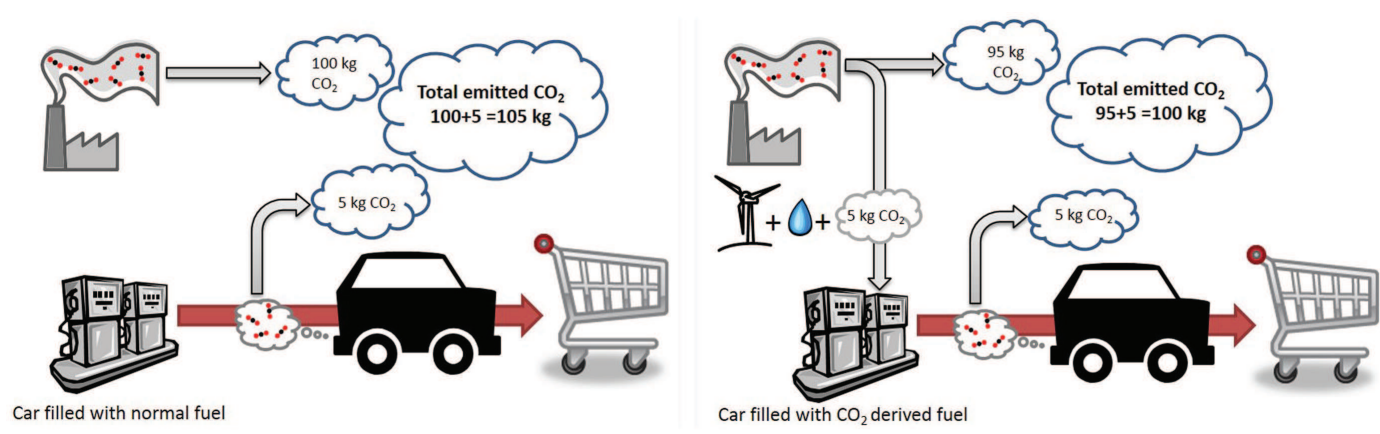

FIGURE 2 |The concept of avoided carbon. Emissions based on no carbon capture and fossil-derived transport fuel (left) and no capture but $5 \%$ conversion of industrial emissions into synthetic transport fuel (right). 
Table 2 | Current $\mathrm{CO}_{2}$ utilization technologies and forecasts for 2016 [adapted from Aresta et al. (2013)]

\begin{tabular}{lcccc}
\hline Compound & $\begin{array}{c}\text { Total } \\
\text { production by } \\
\text { all methods } \\
\text { (Mt/year) }\end{array}$ & $\begin{array}{c}\mathbf{C O}_{\mathbf{2}} \text { used in } \\
\mathbf{C O}_{\mathbf{2}} \text {-derived } \\
\text { production } \\
\text { (Mt/year) }\end{array}$ & $\begin{array}{c}\text { 2016 Total } \\
\text { production } \\
\text { forecast } \\
\text { (Mt/year) }\end{array}$ & $\begin{array}{c}\mathbf{2 0 1 6} \mathbf{C O}_{\mathbf{2}} \\
\text { (Meeded } \\
\text { (Mt/year) }\end{array}$ \\
\hline Urea & 155 & 114 & 180 & 132 \\
Methanol & 50 & 8 & 60 & 10 \\
DME & 11.4 & 3 & $>20$ & $>5$ \\
TMBE & 30 & 1.5 & 40 & 3 \\
Formaldehyde & 21 & 3.5 & 25 & 5 \\
Polycarbonates & 4 & 0.01 & 5 & 1 \\
Carbamates & 5.3 & 0 & $>6$ & 1 \\
Polyurethanes & $>8$ & 0 & 10 & 0.5 \\
Acrylates & 2.5 & 0 & 3.0 & 1.5 \\
Inorganic & 200 & $c a .50$ & 250 & 70 \\
carbonates & & 180 & & 256 \\
Total & & & & \\
\hline
\end{tabular}

Table 3 | Net sequestration of $\mathrm{CO}_{2}$ by the different mitigation technologies for "cradle to gate" analyses.

\begin{tabular}{|c|c|c|}
\hline Process & $\begin{array}{c}\text { Net } \mathrm{CO}_{2} \text { sequestered } \\
\text { or used } / \mathrm{kg} \mathrm{m}^{-3}\end{array}$ & Product \\
\hline $\operatorname{ccs}$ & 469 & No product \\
\hline Immiscible $\mathrm{CO}_{2}$-EOR & 469 & Crude oil \\
\hline Miscible $\mathrm{CO}_{2}$-EOR & 234.5 & Crude oil \\
\hline CDU $100 \%$ conversion & 469 & $\mathrm{C}_{19} \mathrm{H}_{40}$ \\
\hline CDU 70\% conversion & 328 & $\mathrm{C}_{19} \mathrm{H}_{40}$ \\
\hline CDU $50 \%$ conversion & 234.5 & $\mathrm{C}_{19} \mathrm{H}_{40}$ \\
\hline
\end{tabular}

give a $2 \mathrm{~m}^{3}$ mixed solution. A $1 \mathrm{~m}^{3}$ sample will therefore contain $234.5 \mathrm{~kg} \mathrm{CO}_{2}$ and $450 \mathrm{~kg}$ crude oil. The mixture released at the well head will therefore also contain $450 \mathrm{~kg}$ oil and $234.5 \mathrm{~kg}$ $\mathrm{CO}_{2}$ will be either released to the atmosphere or re-injected into the well in a recycle process. However, to keep boundaries consistent, we will take this $234.5 \mathrm{~kg} \mathrm{CO}_{2}$ as being non-sequestered. The amount of $\mathrm{CO}_{2}$ remaining in the well will be $234.5 \mathrm{~kg}$ and the net sequestration will be $+234.5 \mathrm{~kg} \mathrm{CO}_{2}$.

For CDU, we also make an extreme assumption: complete conversion of $\mathrm{CO}_{2}$ to $-\mathrm{CH}_{2}$ - by catalytic Fischer-Tropsch-type reduction. Again, the functional unit is $1 \mathrm{~m}^{3} \mathrm{CO}_{2}(469 \mathrm{~kg}, 10.66 \mathrm{kmol})$, which is converted to $10.66 \mathrm{kmol}-\mathrm{CH}_{2}$ - units, or $0.65 \mathrm{kmol}$ $\mathrm{C}_{19} \mathrm{H}_{40}$ molecules. For complete conversion, the net amount of $\mathrm{CO}_{2}$ sequestered is $469 \mathrm{~kg}$. We can also consider other lower concentrations whereby $70 \%$ conversion would produce $0.46 \mathrm{kmol}$ product and $50 \%$ conversion would produce $0.33 \mathrm{kmol}$ product. The net capture is defined as the amount entering the system minus the amount emitted. For 100,70 , and $50 \%$ conversion, the net amount of $\mathrm{CO}_{2}$ sequestered is therefore 469,328 , and $234.5 \mathrm{~kg}$, respectively. The scenarios are summarized in Table 3 .

As stated, this gives a "cradle to gate" analysis that does not take account of any emissions originating from the product. One of the concerns raised against $\mathrm{CDU}$ is that any fuels produced will be eventually re-released to the atmosphere. While this is certainly true, any fuels originating from EOR needs to be considered similarly. Obviously, there will be no emissions as a result of CCS so the net emissions reduction will remain at $469 \mathrm{~kg}$. However, CCS does incur considerable CAPEX and OPEX costs through capture and pipeline construction to the storage site; and solvent regeneration, replacement, and gas compression, respectively. If we consider that immiscible EOR releases $900 \mathrm{~kg}$ crude oil with an average molecular weight of $248 \mathrm{~kg} \mathrm{kmol}^{-1}\left(\mathrm{C}_{19} \mathrm{H}_{40}\right)$, then the production is $3.63 \mathrm{kmol}$. On complete combustion, each molecule of oil will release 19 molecules of $\mathrm{CO}_{2}(69.4 \mathrm{kmol})$ with a mass of $3,051 \mathrm{~kg}$. This has a significant effect on the net emissions. The "cradle to gate" emissions reduction of $+469 \mathrm{~kg}$ then becomes $-2,582 \mathrm{~kg}$ emitted once the "cradle to grave" scenario is implemented. For the miscible $\mathrm{CO}_{2}$-EOR case, the $450 \mathrm{~kg}$ oil produced will release $1,526 \mathrm{~kg}$ of $\mathrm{CO}_{2}$ on complete combustion. The "cradle to grave" emissions now become $-1,292 \mathrm{~kg}$ which is obviously lower than the immiscible case, however less fuel is produced and so lower profit is achieved.

The "cradle to grave" analysis for $\mathrm{CDU}$ is interesting. The conversion takes $469 \mathrm{~kg}$ (10.66 kmol) $\mathrm{CO}_{2}$ and converts it to $0.56 \mathrm{kmol}$ $(139 \mathrm{~kg}) \mathrm{C}_{19} \mathrm{H}_{40}$. Combustion simply converts this back to $469 \mathrm{~kg}$ $\mathrm{CO}_{2}$ so there is no net emission over the process. Therefore, $469 \mathrm{~kg}$ $\mathrm{CO}_{2}$ are consumed in producing the fuel and $469 \mathrm{~kg}$ are emitted through its subsequent combustion, net emissions are zero. However, there is an added bonus, as the $\mathrm{CO}_{2}$-derived fuel will be used in place of a fossil fuel, therefore giving a net emissions reduction of $+469 \mathrm{~kg}$. If the "cradle to grave" scenario is employed, this is much more environmentally benign than either of the EOR processes.

When considering the production of a fuel, it is more usual to define a quantity of the product as the functional unit. In this case, we will define it as $1 \mathrm{t}$ of oil extracted in EOR or $1 \mathrm{t}$ of synthetic fuel produced from $\mathrm{CO}_{2}$. From CDU, $139 \mathrm{~kg}$ synthetic fuel $\left(\mathrm{C}_{19} \mathrm{H}_{40}\right)$ is produced from $469 \mathrm{~kg} \mathrm{CO}$. Therefore, the production of $1 \mathrm{t}$ synthetic fuel consumes $3.37 \mathrm{t} \mathrm{CO}_{2}$. For immiscible EOR, $900 \mathrm{~kg}$ crude oil $\left(\mathrm{C}_{19} \mathrm{H}_{40}\right)$ is produced from $469 \mathrm{~kg} \mathrm{CO}_{2}$ and hence $1 \mathrm{t}$ of oil is produced using $521 \mathrm{~kg} \mathrm{CO}$. This means 6.5 times more $\mathrm{CO}_{2}$ is sequestered in the $\mathrm{CDU}$ process than in immiscible EOR. This is summarized in Table 4.

Returning to the database of CCS projects, it can be noted that of the projects in the Operate phase, 11 are EOR projects and 2 are geological storage projects. Based on our calculations above and assuming an immiscible system, these EOR CCS projects would actually result in $\mathrm{CO}_{2}$ emissions of $128 \mathrm{Mt} /$ year from the combusted oil products. When you then consider the projects in the Execute and Define stages, the situation does improve but not dramatically. In the Execute stage, 6 of 9 projects are EOR resulting in net emissions of $38 \mathrm{Mt} /$ year and in the Define stage, 8 of 14 projects are EOR giving $59 \mathrm{Mt} /$ year $\mathrm{CO}_{2}$ emitted on the combustion of the produced oil (Table 5). Combining all $\mathrm{CO}_{2}$ produced by combusting the EOR products, we would need over 200 extra geological storage-based CCS facilities to sequester the $\mathrm{CO}_{2}$ emitted from EOR. This is 18 times the number of geological storage projects planned in these three phases. Obviously, this is far from ideal and is not practically possible. Therefore, it is our opinion that EOR should not be considered as a mitigation technology and instead we should be investing in CDU-based fuels. We acknowledge the 
Table 4 | Comparisons of net $\mathrm{CO}_{2}$ emissions using the CCS, EHR, and CDU strategies discussed.

\begin{tabular}{lclccc}
\hline Process & $\mathbf{C O}_{\mathbf{2}} \mathbf{~ u s e d} / \mathbf{k g}$ & Product & $\begin{array}{c}\text { Amount of } \\
\text { product }\end{array}$ & $\begin{array}{c}\text { Amount of } \mathbf{C O}_{\mathbf{2}} \text { released } \\
\text { when product combusted/kg }\end{array}$ & $\begin{array}{c}\text { Net } \mathbf{C O}_{\mathbf{2}} \text { sequestered } \\
\text { or offset/kg }\end{array}$ \\
\hline $\mathrm{CCS}$ & 469 & No product & 0 & 0 & 469 \\
Immiscible $\mathrm{CO}_{2}$-EOR & 469 & Crude oil & 900 & 3,051 & $-2,582$ \\
Miscible $\mathrm{CO}_{2}$-EOR & 234.5 & Crude oil & 450 & 1,526 & $-1,291.5$ \\
$\mathrm{CDU} 100 \%$ conversion & 469 & $\mathrm{C}_{19} \mathrm{H}_{40}$ & 139 & 469 & 469 \\
CDU 70\% conversion & 328 & $\mathrm{C}_{19} \mathrm{H}_{40}$ & 97 & 328 & 328 \\
CDU 50\% conversion & 234.5 & $\mathrm{C}_{19} \mathrm{H}_{40}$ & 69.5 & 234.5 & 234.5 \\
\hline
\end{tabular}

Table 5 | Analysis of $\mathrm{CO}_{2}$-EOR projects and further mitigation requirements needed to handle additional $\mathrm{CO}_{2}$ emissions

\begin{tabular}{|c|c|c|c|}
\hline & Operate & Execute & Define \\
\hline $\begin{array}{l}\mathrm{CO}_{2} \text { sequestered in EOR } \\
\text { (Mt/year) }\end{array}$ & 25.00 & 7.50 & 11.46 \\
\hline Volume $\mathrm{CO}_{2}\left(\mathrm{~m}^{3} /\right.$ year $)$ & $50,403,226$ & $15,120,968$ & $23,104,839$ \\
\hline Mass crude (Mt/year) & 45 & 14 & 21 \\
\hline $\begin{array}{l}\text { Mass } \mathrm{CO}_{2} \text { in burnt crude } \\
\text { (Mt/year) }\end{array}$ & 153 & 46 & 70 \\
\hline Total $\mathrm{CO}_{2}$ emitted (Mt/year) & 128 & 38 & 59 \\
\hline $\begin{array}{l}\text { Amount } \mathrm{CO}_{2} \text { stored in geological } \\
\text { storage (Mt/year) }\end{array}$ & 1.6 & 5.5 & 12.4 \\
\hline No of CCS geological projects & 2 & 3 & 6 \\
\hline $\begin{array}{l}\text { Average geological storage per } \\
\text { project (Mt/year) }\end{array}$ & 0.8 & 1.8 & 2.1 \\
\hline $\begin{array}{l}\text { Total number extra geological } \\
\text { storage projects needed to } \\
\text { remove EOR- } \mathrm{CO}_{2}\end{array}$ & 160 & 21 & 28 \\
\hline
\end{tabular}

economic potential of EOR versus geological storage CCS and therefore why it is an attractive option. However, when discussing $\mathrm{CO}_{2}$ mitigation, EOR simply cannot be considered a mitigation strategy when a "cradle to grave scenario" is applied. The market for hydrocarbon fuels is large, and economics drives the push for extracting evermore harder to reach oil sources, but this just further exasperates our $\mathrm{CO}_{2}$ problem. The conversion of $\mathrm{CO}_{2}$ into synthetic hydrocarbon fuels would satisfy our demand whilst limiting the environmental consequences.

\section{$\mathrm{CO}_{2}$ UTILIZATION POTENTIAL}

As described above, EHR/EOR will result in more $\mathrm{CO}_{2}$ emissions. CCS will reduce emissions but at a cost and the projected rate of deployment is modest. But what about CDU?

Though significant amounts of $\mathrm{CO}_{2}$ are being currently utilized, the potential is much higher. $\mathrm{CO}_{2}$ can be used as the carbon source in a wide variety of products and hence the volume of $\mathrm{CO}_{2}$ that can be utilized is high. In Figure 3, we have produced a scenario for $\mathrm{CO}_{2}$ utilization, which incorporates current uses such as urea production and replaces fossil oils in other processes to produce a small range of organic chemicals, diesel and aviation fuel, methane (synthetic natural gas), and some polymers. The case of urea is interesting. While current processes rely on hydrogen derived from fossil fuel sources, there is a drive to produce "green" hydrogen through the electrolysis of water using excess intermittent renewable energy supplies such as wind and solar. In the final section, we will consider the practicality of such an approach. We have also included the mineralization of industrial wastes providing long-term $\mathrm{CO}_{2}$ sequestration and construction materials. The potential for the creation of mineralized products from $\mathrm{CO}_{2}$ is in reality much higher, however this often involves mineralizing substances such as olivine or serpentine, which will first have to be mined. Therefore, to negate environmental impacts of mining, we have only included the mineralization of waste such as fly ash, bauxite, and steel slags. Mineralizing these wastes to turn them into commercially useful construction materials provides a favorable greener alternative to traditional disposal and should be prioritized in $\mathrm{CO}_{2}$ mineralization.

The graph in Figure 3 proposes the quantity of $\mathrm{CO}_{2}$ that could be utilized at different market shares based on current levels of production and compares this against $\mathrm{CO}_{2}$ reduction targets for the EU and the World in CCS, and EU and USA overall $\mathrm{CO}_{2}$ reduction targets. It can be observed that only producing $10 \%$ of each product would make significant inroads into the EU CCS target or exceed it. The potential for diesel, aviation fuel, and methane (as a synthetic replacement for natural gas) is high due to the large quantities consumed per annum. As discussed previously, although the majority of these products are produced to provide energy via combustion, hence re-releasing the $\mathrm{CO}_{2}$, the net reduction in $\mathrm{CO}_{2}$ emitted due to switching from fossil sources will be significant. A scenario whereby $100 \%$ of the current urea, $20 \%$ of specific chemicals, $30 \%$ waste mineralization, $20 \%$ of specific polymers, $5 \%$ diesel and aviation fuel, and $10 \%$ methane are produced using $\mathrm{CO}_{2}$ is shown in the graph in Figure 3. This scenario (purple bar) represents a realistic yet challenging estimate for CDU deployment by the year 2030. In this scenario, $1.34 \mathrm{Gt}$ of $\mathrm{CO}_{2} /$ year would be utilized. This amount of $\mathrm{CO}_{2}$ is equal to $95 \%$ of the $\mathrm{CO}_{2}$ that must be reduced in the EU by 2030, and is equivalent to $83 \%$ of the world target for CCS by 2030.

However, one question that must be addressed is how realistic is the possibility of CDU deployment on this scale. Worldwide there are a number of commercial and pilot scale CDU projects. Carbon Recycling International in Iceland is producing 5 million liters $(950 \mathrm{t})$ of renewable methanol per annum from $\mathrm{CO}_{2}$ accounting for $1.5 \%$ of world production. The company has plans to expand production to bring renewable methanol to a global market outside Iceland in partnership with Methanex (the world's largest methanol supplier). Bayer Material Science has recently invested $€ 15$ million in the construction of the world's first commercial 


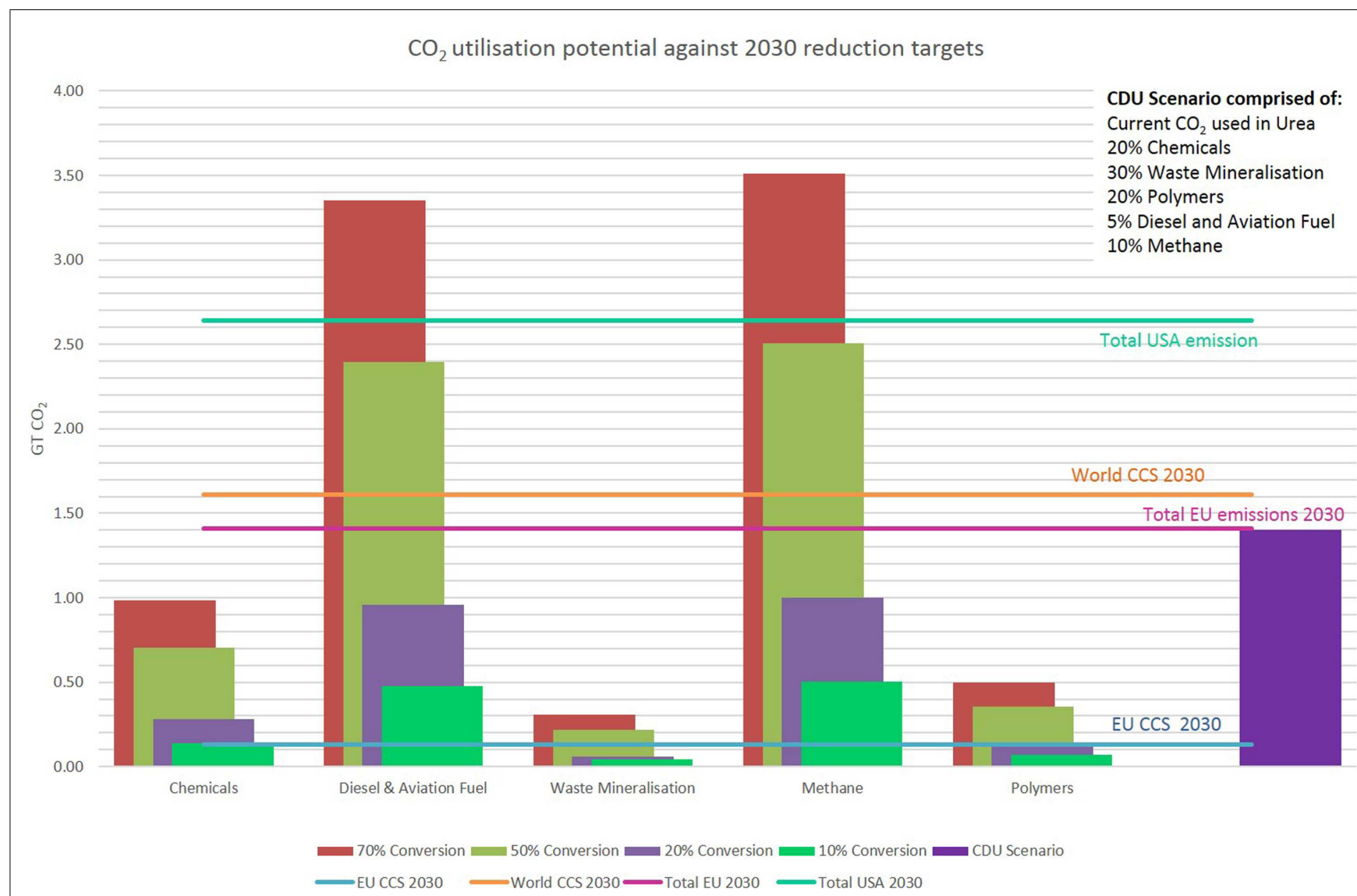

FIGURE 3 | Replacement of fossil-derived chemicals and fuels by CDU replacements assessed against $\mathrm{CO}_{2}$ emission reduction targets in the EU, USA, and globally.

plant to produce polyols from $\mathrm{CO}_{2}$ as a precursor for $\mathrm{CO}_{2}$-based polyurethane foams. Based in Dormagen, the plant will manufacture $5 \mathrm{kt} /$ year with the aim to have the first commercial $\mathrm{CO}_{2}$-based polyols on the market by 2016. Novomer, a USA-based company, has commercialized a range of $\mathrm{CO}_{2}$ polyols under the trade name Converge ${ }^{\circledR}$. The polymers contain up to $50 \% \mathrm{CO}_{2}$ by mass and are based on a proprietary catalyst system that produces low-cost polyols and polymers for a wide variety of applications. They currently have a 5-kt/year of capacity and have begun a plant design process to expand to make $100 \mathrm{kt}$ for 2017. KOGAS DME Activities for Commercialization (2011) in Korea has been manufacturing DME from $\mathrm{CO}_{2}$ since 2000 on demonstration and pilot scale plants. KOGAS' next phase will be a commercialized process producing 3,000 t/day of DME. The Jiangsu Jinlong-CAS Chemical Co. Ltd. in Taixing, China uses waste $\mathrm{CO}_{2}$ from ethanol manufacture to produce polypropylene and polyethylene carbonate polyol to be used as flame retardant exterior wall insulation. By 2015, it aims to have expanded production to utilize $80 \mathrm{kt} /$ year $\mathrm{CO}_{2}$. The Asahi Kasei Chemicals Corporation's phosgene-free process to manufacture polycarbonate from $\mathrm{CO}_{2}$ has been licensed to multiply companies. Five-hundred ninety-five kilotonne per year of polycarbonates are manufactured annually using this green process resulting in a reduction in $\mathrm{CO}_{2}$ emissions of $102 \mathrm{kt} /$ year. This is equivalent to the proposed full global CCS plant capacity by 2020 .
Skyonic has opened its first commercial $\mathrm{CO}_{2}$ utilization plant in San Antonio. The plant directly captures $75 \mathrm{kt} /$ year $\mathrm{CO}_{2}$, which is used to manufacture salable products such as sodium bicarbonate and sodium carbonate, and bi-products such as bleach and hydrochloric acid. Skyonic have calculated along with the $\mathrm{CO}_{2}$ utilized in the process, an additional $225 \mathrm{kt}$ of $\mathrm{CO}_{2}$ will be offset by the production of green by-products. These examples show that $\mathrm{CO}_{2}$ utilization is becoming a commercial reality, with potential to make a significant difference in the amount of $\mathrm{CO}_{2}$ emitted and in creating a greener, sustainable chemical industry.

\section{CONSIDERATION OF CDU AND CCS AT A POINT SOURCE EMITTER}

The UK has announced two potential CCS facilities at power stations in Yorkshire (White Rose Project, Drax) and Scotland (Peterhead). The former is an oxy-fuel facility while the latter is a post-combustion amine capture facility. To put the argument in favor of CDU into context, we will consider the Peterhead facility as a base case. The plant will capture part of the total plant emissions, $1 \mathrm{Mt} /$ year $\mathrm{CO}_{2}$, which will then be piped to a geological storage site in the North Sea. So how does that $1 \mathrm{Mt} /$ year storage capacity compare with what could be achieved through CDU? 


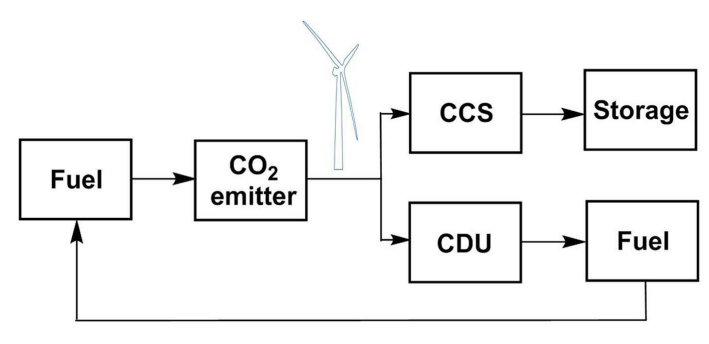

FIGURE 4 | Schematic representation a CDU recycling process in a combined CCS-CDU capture system, using wind energy to power the process.

The Peterhead plant has a proposed $\mathrm{CO}_{2}$ capture capacity of $1 \mathrm{Mt} /$ year, which equates to $2.74 \mathrm{kt} /$ day or $114.2 \mathrm{t} / \mathrm{h}$. So how much hydrogen is needed to convert this to synthetic oil? If $1 \mathrm{Mt} /$ year $\mathrm{CO}_{2}$ were to be converted into synthetic oil, this would produce $0.30 \mathrm{Mt} /$ year product as the functional unit of $1 \mathrm{t}$ synthetic oil would require $3.37 \mathrm{t} \mathrm{CO}_{2}$. So each day, $274 \mathrm{kt} \mathrm{CO}_{2}$ would be captured by the plant and this would be reduced to produce the synthetic oil. To a good approximation, each $\mathrm{CO}_{2}$ molecule is reduced to one $-\mathrm{CH}_{2}$ - sub-unit and two molecules of water. Therefore, for each $\mathrm{CO}_{2}$ reduction, three equivalents of hydrogen are needed. This means that $44 \mathrm{t} \mathrm{CO}_{2}$ will require $6 \mathrm{t}$ hydrogen to produce $14 \mathrm{t}$ of equivalent $-\mathrm{CH}_{2}$ - sub-unit and $36 \mathrm{t}$ water. Therefore, $1 \mathrm{Mt} \mathrm{CO}_{2}$ will require $0.136 \mathrm{Mt} /$ year $\mathrm{H}_{2}$ to produce $0.30 \mathrm{Mt} /$ year synthetic oil.

Over a 24-h period from 20:30 on 16 December, 2014 to 20:30 17 December, 2014, the average UK wind generation was $114,170 \mathrm{MWh}$, representing $12.1 \%$ of the UK energy mix. If all the wind energy were converted to hydrogen through water hydrolysis, how much would be produced? Boretti (2012) has reported that the production of $1 \mathrm{~kg}$ of hydrogen requires $53 \mathrm{kWh}$ electricity to power the process. This is equivalent to $53 \mathrm{MWh} / \mathrm{t} \mathrm{H}_{2}$ produced, which is $0.019 \mathrm{t}(19 \mathrm{~kg}) \mathrm{H}_{2} / \mathrm{MWh}$. Therefore, in the generation period described $114,170 \mathrm{MWh}$ would produce $2,169 \mathrm{t}$ $\mathrm{H}_{2}$. If Peterhead is capturing $114.2 \mathrm{t} / \mathrm{h} \mathrm{CO}$, this will need $15.6 \mathrm{t} / \mathrm{h}$ $\mathrm{H}_{2}$. Expressed as a total of the wind generation, this is $0.7 \%$. Therefore, diverting less than $1 \%$ of the renewable wind energy to synthetic oil production would remove the need for the captured $\mathrm{CO}_{2}$ to be sequestered geologically. Of course, there are times when there is insufficient wind, or base line power consumption is high, so that this renewable energy cannot be diverted (Hall et al., 2014). However, there are also times when wind production exceeds baseline demand, for example in summer. While it is usually customary in such cases to turn off the wind turbines, we suggest that it is more environmentally and economically beneficial to utilize that excess energy to store it chemically for future use. This provides an alternative for just CCS. By adding CDU, this allows capture capacity to be diverted from a waste stream to a product stream, thereby generating income; or adding additional capacity to capture more $\mathrm{CO}_{2}$ and ultimately increase the environmental credentials by avoiding more fossil fuel use. This is summarized schematically in Figure 4, which shows how a carbon cycle can be developed as a means for seasonal energy storage. If the fuel is diverted to the transport sector, then the additional use of direct air capture of $\mathrm{CO}_{2}$ must also be considered.

\section{CONCLUSION}

In conclusion, although geological CCS will provide a reduction in the $\mathrm{CO}_{2}$ emitted to the environment, the projected capacity of CCS projects is just not on a scale compared with the $\mathrm{CO}_{2}$ reductions that are needed. Twenty-two CCS projects are described as being in the Operate or Execute phase with a projected capture capacity of approximately $40 \mathrm{Mt}$ /year by 2018 . However, the IEA target for CCS for 2020 is $60 \mathrm{Mt}$ /year (Energy Technology Perspectives, 2014) and of these 17 are EHR projects which when considering net "cradle to grave" emissions will produce further $\mathrm{CO}_{2}$ emissions of $166 \mathrm{Mt}$ /year. In comparison $\mathrm{CO}_{2}$ utilization projects are in operation, are growing in deployment and are providing a net reduction in $\mathrm{CO}_{2}$ both by utilizing $\mathrm{CO}_{2}$ in production and by providing a new fossil-free source for these products. It can be argued that in terms of emissions EHR is better than non-EOR oil production as some $\mathrm{CO}_{2}$ is sequestered. However, when one considers the large amounts of $\mathrm{CO}_{2}$ produced when oil is combusted, we would have a far greater chance of limiting climate change if we switch from oil-based fuels to $\mathrm{CO}_{2}$ utilization-based synthetic fuels. However, CDU capacity is currently higher (180 Mt/year) that operational CCS capacities (26.6 Mt/year) and utilization is predicted to reach $256 \mathrm{Mt}$ /year by 2016 , again much higher than CCS. This trend is likely to persist as more CDU processes move from laboratory to demonstrator scale.

Furthermore, CDU can provide carbon-neutral fuels and other products that while net sequestration may be lower than in the case of CCS do add valuable products into the economy. EHR will remain a means for economic benefit but cannot be considered as a mitigation technology as it ultimately emits more carbon dioxide than it sequesters through product use. If immiscible EHR is compared against mitigation potential for CDU and CCS, the figures are $+2,582: 0:-469$ respectively where a negative value represents sequestration and a positive value an emission.

Carbon dioxide utilization will provide much needed additional capacity, with profit, in the move toward a low carbon economy. $\mathrm{CO}_{2}$ is used as a resource, not a waste. Like CCS, it should be regarded as one of the key emissions mitigation technologies in the fight against climate change. However, the same cannot be said of EHR which will ultimately lead to net $\mathrm{CO}_{2}$ emissions.

\section{REFERENCES}

Aresta, M., and Dibenedetto, A. (2010). "Indirect utilization of carbon dioxide: Utilization of Terrestrial and Aquatic Biomass," in Carbon Dioxide as Chemical Feedstock, ed. M. Aresta (Weinheim: Wiley-VCH Verlag GmbH \& Co, KGaA), 335-351.

Aresta, M., Dibenedetto, A., and Angelini, A. (2013). The changing paradigm in $\mathrm{CO}_{2}$ utilization. J. CO2 Utilization 3-4, 65-73. doi:10.1016/j.jcou.2013.08.001

Aresta, M., Dibenedetto, A., and Barberio, G. (2005). Utilization of macroalgae for enhanced $\mathrm{CO}_{2}$ fixation and biofuels production: development of a computing software for an LCA study. Fuel Process Technol. 86, 1679-1693. doi:10.1016/j.fuproc.2005.01.016

Asahi Kasei Chemicals. Available at: http://www.asahi-kasei.com/chemicals/en/

Bayer Material Science. Available at: http://www.press.bayer.com/baynews/baynews. nsf/id/Using-CO2-EUR-15-million-for-new-production-line

Berners-Lee, M., and Clark, D. (2013). The Burning Question: We Can't Burn Half the World's Oil, Coal and Gas. So How Do We Quit? London: Profile Books. ISBN: 9781781250457 . 
Boretti, A. (2012). Renewable hydrogen to recycle $\mathrm{CO}_{2}$ to methanol. Int. J. Hydrogen Energy 38, 1806-1812. doi:10.1016/j.biortech.2008.02.061

Carbon Dioxide Information Analysis Centre. (2014). Available at: cdiac.ornl.gov/GCP/carbonbudget/2013/

Carbon Recycling International. Available at: http:/www.carbonrecycling.is/

Centi, G., Perathoner, S., and Iaquaniello, G. (2013). $\mathrm{CO}_{2}$ : A Valuable Source of Carbon, eds M. De Falco, G. Iaquaniello, and G. Centi (London: Springer-Verlag).

Global CCS Institute database. (2014). Available at: http://www.globalccsinstitute. com/projects/large-scale-ccs-projects

Hall, P. J., Wilson, I. A. G., and Rennie, A. (2014). " $\mathrm{CO}_{2}$-derived fuels for energy in carbon dioxide utilisation," in Closing the Carbon Cycle, eds P. Styring, E. A. Quadrelli, and K. Armstrong (Amsterdam: Elsevier), 33-44.

IEA Energy Technology Perspectives. (2014). Harnessing Electricity's Potential. Paris: IEA Publications. ISBN 978-92-64-20800-1, OECD/IEA.

IPCC. (2007). Scenario Analysis and Analysis of Stabilisation Targets, Climate Change 2007, 19.4.2.2: Working Group II: Impacts, Adaptation and Vulnerability. Available at: http://www.ipcc.ch

Jansen, D., Styring, P., de Coninck, H., Reith, H., and Armstrong, K. (2011). Carbon Capture and Utilization in the Green Economy. Sheffield: CO2Chem Media and Publishing. ISBN: 978-0-9572588-1-5.

Jiangsu Jinlong-CAS Chemical Co. Ltd. Available at: http://www.zkjlchem.com

KOGAS DME Activities for Commercialization. (2011). (last accessed 19/12/2014)

McGlade, C., and Ekins, P. (2015). The geographical distribution of fossil fuels unused when limiting global warming to $2^{\circ} \mathrm{C}$. Nature 517, 187. doi:10.1038/ nature 14016

Novomer. Available at: http://www.novomer.com/
Skyonic. Available at: www.skyonic.com/

Styring, P., Quadrelli, E. A., and Armstrong, A. (2014). "Preface in carbon dioxide utilisation," in Closing the Carbon Cycle, eds P. Styring, E. A. Quadrelli, and K. Armstrong (Amsterdam: Elsevier).

World Energy Council. (2013). "Time to get real - the case for sustainable energy investment," in World Energy Trilemma 2013, ed. O. Wyman (London: World Energy Council). ISBN: 9780946121229.

Conflict of Interest Statement: The authors declare that the research was conducted in the absence of any commercial or financial relationships that could be construed as a potential conflict of interest.

Received: 05 January 2015; paper pending published: 19 January 2015; accepted: 08 February 2015; published online: 03 March 2015.

Citation: Armstrong K and Styring P (2015) Assessing the potential of utilization and storage strategies for post-combustion $\mathrm{CO}_{2}$ emissions reduction. Front. Energy Res. 3:8. doi: 10.3389/fenrg.2015.00008

This article was submitted to Carbon Capture, Storage, and Utilization, a section of the journal Frontiers in Energy Research.

Copyright (C) 2015 Armstrong and Styring. This is an open-access article distributed under the terms of the Creative Commons Attribution License (CC BY). The use, distribution or reproduction in other forums is permitted, provided the original author(s) or licensor are credited and that the original publication in this journal is cited, in accordance with accepted academic practice. No use, distribution or reproduction is permitted which does not comply with these terms. 